\title{
Dialéctica de la justicia. Una apología de Platón como crítico social
}

\author{
Rodrigo Maruy van den Broek \\ Pontificia Universidad Católica del Perú
}

Resumen: Este artículo sostiene que Platón constituye un interlocutor fructífero para la Teoría crítica. Desde un diálogo con Axel Honneth, argumentaremos primero que la metodología de crítica social desarrollada en la República posee elementos constructivo-racionales y reconstructivo-hermenéuticos. Luego, enfatizaremos dos conceptos prefigurados en dicha obra que, mediante Hegel, yacen en el trasfondo de la Teoría crítica, a saber: holismo y patología social. Ello nos permitirá articular, como conclusión, una "dialéctica de la justicia" que, en el sentido de Adorno \& Horkheimer, recorre la obra de Honneth.

Palabras clave: República, Honneth, Hegel, holismo, unidad, patología social

\begin{abstract}
Dialectic of Justice. An Apology of Plato as a Social Critic". This paper holds that Plato constitutes a fruitful interlocutor for Critical theory. In opposition to Axel Honneth's claims, we argue in the first place that the methodology of social criticism developed in the Republic contains constructive-rational and reconstructive-hermeneutic elements altogether. We shall then emphasize two concepts that are prefigured in this text and that, through Hegel, lie in the background of Critical theory, namely: holism and social pathology. This will allow us to articulate, as a conclusion, a "dialectic of justice" which, in Adorno \& Horkheimer's sense, traverses Honneth's work.
\end{abstract}

Key words: Republic, Honneth, Hegel, holism, unity, social pathology 
The safest general characterization of the European philosophical tradition is that it consists of a series of footnotes to Plato.

Alfred N. Whitehead, 1978, 39

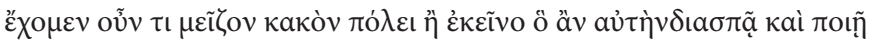

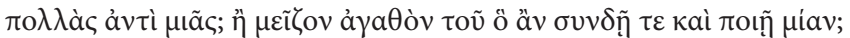
Platón, República, 462a-b

\section{§1. Introducción}

Un fantasma recorre la Teoría Crítica: el fantasma de Platón. Para empezar, se diría con justicia que Platón es un filósofo idealista; es decir, cree en la existencia de 'ideas' o'formas' abstractas e inmutables, cuya contemplación implica un rotundo desprecio de los sentidos. Además, Platón es un defensor del dualismo o, en otras palabras, considera que dichas 'formas' habitan un mundo inteligible radicalmente trascendente respecto de nuestro mundo sensible. En tal sentido, el fundamento último de la realidad, 'la Idea del Bien', se encuentra más allá del conocimiento humano, de modo que su filosofía desemboca de manera inexorable en una suerte de unión mística con Dios. Finalmente, Platón también glorifica un Estado autoritario, donde los individuos deben someterse al mandato incuestionable del 'rey filósofo', quien por su parte es dueño de las leyes y de los principios que gobiernan, perennes, el devenir de la historia. Por todos estos motivos, es un alivio que las nuevas generaciones de la Teoría Crítica hayan podido superar los vestigios míticos y totalizantes que definen la obra de Platón.

Todas y cada una de las afirmaciones del párrafo anterior son falsas, salvo quizás la primera. En efecto, a pesar de que la literatura especializada haya hecho patente el carácter irrisorio y unilateral de tamaños prejuicios, es digno de asombro que algunos de ellos resuenen aún en los escritos de autores contemporáneos no poco influyentes en el ámbito de la crítica social'. Acaso ha de encontrarse un ejemplo paradigmático en la obra de Axel Honneth y, más precisamente, en su Crítica reconstructiva de la sociedad con

1 Es importante reconocer que la presente introducción reproduce casi a cabalidad la misma estrategia retórica que emplea Terry Pinkard (2000, ix) para inaugurar su obra Hegel: $A$ Biography. 
salvedad genealógica (2000). En aquel texto, se aborda la pregunta acerca de cómo obtener criterios legítimos que posibiliten el desarrollo de una crítica social fundada y, por implicación, efectiva. No se trata, dicho sea de paso, de un problema menor, sino de una consideración metodológica crucial en lo que respecta al legado (y al porvenir) de la Escuela de Frankfurt. Con la finalidad de introducir su propuesta, Honneth se remitirá nada menos que a Michael Walzer y, en particular, a su Interpretación y crítica social (1987). En esta obra, Walzer plantea una importante distinción entre tres modelos de crítica, a saber: la 'revelación', la "invención” y la "interpretación". Por su parte, Honneth propondrá descartar la primera vía y, acto seguido, designará a las otras dos respectivamente como "construcción" $y$ "reconstrucción" (2000, 731-732). No obstante, tal vez el aporte más novedoso de este texto consista, antes bien, en la incorporación de una "salvedad genealógica"; esto es, un modelo parasitario de crítica, el cual le permitirá a Honneth evitar las peligrosas tendencias conservadoras que impregnaban la vía de la interpretación (732-733).

Ahora bien, en lo que nos concierne, vale la pena explicitar detalladamente los motivos que conducen a Honneth a prescindir del primer modelo de crítica social propuesto por Walzer:

El primer tipo [la'revelación'] hace referencia en este contexto a todos los enfoques de crítica social que se basan en una experiencia de evidencia religiosa o cognitiva para poder avanzar hacia un reino de valores universales, hasta entonces inaccesible en términos sociales; aquí es por lo tanto y con toda claridad una especie de platonismo el que proporciona el trasfondo filosófico de los respectivos ideales o principios a la luz de los cuales las circunstancias sociales serán sometidas a una crítica fundada. Por más que en la actualidad se perfilen tendencias intelectuales que vuelven a impulsar esta forma de platonismo, en lo que sigue no tomaré en cuenta este tipo de crítica de la sociedad porque no me parece lo suficientemente relevante desde el punto de vista filosófico (2009, 56; cursivas añadidas).

Sin mayor preámbulo, el objetivo de este artículo consistirá en formular un plaidoyercontra tales acusaciones. Para ello, será necesario evaluar, en primer lugar, hasta qué punto es o no legítimo considerar exclusivamente según el modelo de la revelación las críticas sociales que Platón articula. Así pues, en oposición a Honneth e incluso a Walzer, argumentaremos que la crítica 
platónica de la sociedad resulta ininteligible si no se toma en consideración sus componentes reconstructivo-hermenéuticos y constructivo-racionales. Un caso paradigmático a examinar será, justamente, su República. En segundo lugar, haremos énfasis en dos conceptos claves prefigurados en dicha obra que, a través de la mediación de Hegel, yacen en el trasfondo mismo de la Teoría Crítica y, por lo tanto, no carecen de relevancia filosófica, sino todo lo contrario. Tales conceptos son: holismo y patología social. A modo de conclusión, el análisis de ambos nos permitirá articular una "dialéctica de la justicia" que, en el sentido de Adorno \& Horkheimer, recorre la obra de Honneth. A la luz de estas indagaciones, nuestra defensa sostendrá que Platón, en las antípodas de los prejuicios y de las calumnias que la tradición nos ha legado, constituye de hecho un interlocutor vigente y fructífero para la crítica social contemporánea.

\section{§2. Cuestiones de método: reconstrucción, construcción y descubrimiento}

Antes que nada, sería pertinente considerar una posibilidad que, de ser cierta, minaría todas nuestras intenciones apologéticas o, cuanto menos, las volvería superfluas. En efecto, cuando Honneth habla de "una especie de platonismo" (eine Art von Platonismus) como trasfondo filosófico para el modelo de la 'revelación', ¿se trata de un recurso a la ironía? En otras palabras, ¿se está aludiendo directamente a Platón o, por el contrario, a las caricaturizaciones contemporáneas que lo utilizan, acaso sin saberlo, como una fuente de inspiración normativa? Ello es difícil de determinar, sobre todo porque en el texto no se menciona a ningún autor en específico $\mathrm{y}$, sin más, se procede a discutir el siguiente modelo de crítica social. A manera de pista para evaluar la plausibilidad de esta interpretación quizás demasiado caritativa, constatemos un hecho palpable: Honneth rehúye la metafísica y, por supuesto, la crítica de Platón tiene raigambres metafísicas considerables. De hecho, no es casual que, por emplear un ejemplo ilustrativo, tales reticencias se manifiesten sobre todo en la relación compleja y ambivalente que Honneth establece con Hegel. Piénsese en dos textos de suma importancia: Padecer de indeterminación (1999) y El derecho de la libertad (2011). 
Como bien indica Miguel Giusti, la intención de Honneth en la primera obra referida consiste en actualizar y reconstruir la Filosofía del Derecho (en adelante, $F D$ ), pero "prescindiendo deliberadamente de su dependencia conceptual de la Ciencia de la lógica $(C L)$ " $(2014,124)$. Dicho de otro modo, Honneth no quiere comprometerse ni con el sistema categorial ni con la concepción ontológica del espíritu que Hegel defiende, sino adoptar una perspectiva "posmetafísica" que le permita rescatar la intención básica (Grundabsicht) y estructura global (Grundstruktur) de esta obra $(2014,125)$. Por otro lado, El derecho de la libertad retomará dicho leitmotiv de manera mucho más sustancial al proponerse el esbozo de una"original y afortunada síntesis entre teoría de la justicia (Gerechtigkeitstheorie) y análisis de la sociedad (Gesellschaftsanalyse)" (2014, 126). En otras palabras, Honneth buscará reconstruir normativamente una teoría de la justicia y de la autorrealización de la libertad que no pierda legitimidad en el ámbito "externo" de la moral, pero que tampoco se aferre de manera "interna" y conservadora a las instituciones dadas fácticamente, sino que se desarrolle de forma "inmanente" a partir del grado de realización (Verwirklichung) histórica de los valores que yacen en las presuposiciones estructurales (Strukturvoraussetzungen) de las sociedades contemporáneas (2014 126).

No obstante, uno de los argumentos centrales de Giusti consiste en mostrar que la $C L$ descansa sobre una serie de presuposiciones hermenéuticas que, a su vez, operan como un trasfondo indispensable para comprender la $F D$. Estas presuposiciones refieren al debate que Hegel emprende con la filosofía de su época, el cual sirve como inspiración para el desarrollo de su propia filosofía del espíritu y, concretamente, reflejan la intención por captar en la $F D$ un nuevo tipo de racionalidad que había sido desarrollado justamente en la $C L(2014,130)$. Por lo tanto, "la $F D$ no se entiende sin tomar en consideración el cuestionamiento hegeliano del paradigma de la subjetividad moderna, ni sin la reinterpretación dialéctica del concepto kantiano de autonomía de la voluntad, ni sin la propuesta metodológica del automovimiento del concepto" $(2014,131)$. En conclusión, si bien podría objetarse que esta lectura de la CL es demasiado general o ad hoc, se trata sin duda de una propuesta considerablemente más caritativa y genuinamente hegeliana que la caricaturización de la Lógica como un sistema hermético desligado de motivaciones hermenéuticas (2014, 132). Evidentemente, no 
será muy difícil esbozar un argumento análogo respecto de Platón y sus presuntos 'lastres metafísicos'.

En efecto, ¿hasta dónde podríamos afirmar que Honneth está tomando en consideración las motivaciones hermenéuticas que se esconden detrás del "platonismo"? Ante todo, no es fortuito que emplee el término "revelación" (Offenbarung) para caracterizar este modelo de crítica social $(2000,731)$. De hecho, resulta curioso: si bien Walzer señala que es sobre todo mediante la historia de la religión que conocemos dicho modelo, él lo denomina como "la vía del descubrimiento" (the path of discovery), ya que el énfasis recae no en una experiencia mística de "revelación" divina del "reino", sino en la pretensión por aprehender valores objetivos sub specie aeternitatis (1987, 4-5). Desde esta óptica, las intenciones pragmáticas que se vislumbran a través del uso del término "revelación" y, más precisamente, "reino de valores universales" [Reich allgemein verbindlicher Werte] parecieran sugerir que, así como con Hegel, el problema de Honneth con el "platonismo" reposa en sus compromisos de base con una estructura metafísica que determina la realidad. De ahí que lo considere como un modelo de crítica que no es filosóficamente relevante, equiparable incluso a los diez mandamientos de Moisés. Y sin embargo, no hay que perder de vista que Walzer esboza una distinción explícita entre el "descubrimiento filosófico" y la "revelación religiosa"; distinción que Honneth pasa por alto. En pocas palabras, Walzer señala que la falta de "novedad radical" que es propia de los "descubrimientos filosóficos" (por ejemplo: "no se debe ser indiferente ante el sufrimiento de otras personas") se explica porque, en el fondo, estos remiten a y se basan en características de la vida cotidiana (features of ordinary life) (1987, 6). Siguiendo dicha línea argumentativa, la tesis central del texto de Walzer deviene inteligible: "El descubrimiento filosófico y la invención (dejando de lado la revelación religiosa) son interpretaciones disfrazadas; en realidad, solo hay una vía en la filosofía moral" (1987, 21; cursivas añadidas). Es decir, tanto el esfuerzo crítico por descubrir valores objetivos como por inventar criterios racionales de corte universal parten en última instancia de una interpretación de la moral existente e, incluso, su aceptación (o rechazo) ulterior dependerá también de un ejercicio interpretativo: "todo descubrimiento e invención (la ley divina es un ejemplo obvio) requiere de interpretación" $(1987,26)$. 
Ahora bien, precisamente desde dichas constataciones y contra la tentativa por encasillar y, a fortiori, simplificar la obra de Platón como un modelo más de "revelación", valdría la pena volver a sus textos a fin de repensar las motivaciones hermenéuticas que yacen detrás. En primer lugar, creemos que Schofield tiene razón al recordar que, por ejemplo, la República no es una obra aislada, sino que se enmarca en la tradición literaria de la politeia; término que él traduce como "ciudadanía" y cuyos tratados incluyen, sea de forma implícita o explícita, "un sistema de leyes y prácticas que estructuran la vida de los ciudadanos" $(2006,33)$. Verbigracia, es interesante notar que Hipodamo de Mileto había formulado ya, hacia mediados del siglo V a.C., una división tripartita entre artesanos, agricultores y guerreros como mejor modelo para la polis $(2006,33)$. Así pues, la intención fundamental del texto ha de entenderse desde aquella tradición literaria y en diálogo con el contexto político y social de la época ${ }^{2}$. Consideremos ciertos elementos adicionales. Por un lado, la idea de estructurar la ciudad justa desde una clase civil de "guardianes" es una referencia clara a la organización política de Creta y de Esparta $(2006,39)$. De igual modo, si bien la propuesta educativa de Platón irá considerablemente más allá de la típica agôgê espartana, los guardianes también habrán de vivir y comer juntos en una guarnición tanto en verano como en invierno, y carecerán de propiedad privada, tierras, dinero, oro o plata: es decir, vivirán como se acostumbraba en Esparta con la finalidad de evitar la codicia (pleonexía) $(2006,43,205)$. Es más, el énfasis platónico en la unidad interna y en la concordia (homonoia) de la polis no refleja sino una preocupación común en Atenas tras la derrota en la Guerra del Peloponeso, a saber: la ansiedad frente a la sedición/escisión (stásis) $(2006,218)$. A ello se suman sus conocidas críticas al dinero como divisor de la polis:

2 A propósito de dicha intención fundamentaly contra las interpretaciones superficiales que ven en Platón a un mero crítico de la poesía, es interesante la manera que Gutiérrez presenta a la República como un "encomio de la justicia", de modo que la figura de Sócrates, en tanto guía y educador de la ciudad ideal, habría de reemplazar a la figura misma de Homero, educador histórico de los griegos (2017, 257-258). Entonces, Platón se presenta justamente como un poeta fundador de costumbres, quien apunta incluso a invertir el paradigma homérico. Ello se evidencia, por ejemplo, en que el célebre descenso (katábasis) del filósofo a la caverna no consiste en una experiencia típica para adquirir conocimiento, como era el caso en la tradición homérica, sino todo lo contrario: desciende para enseñar a los prisioneros. Asimismo, Gutiérrez sostiene que "la obra de Platón en general se puede entender como una respuesta a la pregunta por la unidad de la polis, que fue formulada en Grecia una y otra vez desde tiempos arcaicos" $(2017,226)$. 
Platón hizo eco de una larga tradición griega de reflexión política, desde Hesíodo y Solón y a través de escritores de los siglos IV y $\mathrm{V}$ a.C., al ver a la codicia [greed] como una fuerza primaria de destructividad en los asuntos humanos, ya sea al alimentar la stásis dentro de una ciudad, o al impulsar y luego destruir la ambición imperialista, y al enfocarse particularmente en el poder del dinero. $(2006,251)^{3}$

Por otro lado, al justificar la igualdad de funciones entre los géneros y la comunidad de mujeres e hijos, Platón pareciera en cierto sentido responder críticamente a Las asambleístas de Aristófanes, donde tales disposiciones políticas son retratadas como una extravagancia sexual $(2006,229)$. Por último, las objeciones que Platón esgrime contra la democracia y contra Atenas se expresan justamente desde el reconocimiento socrático de la libertad de indagación que dicho sistema permite, como Rowe y Kraut han sabido mostrar ante todo en los diálogos tempranos (citado por Schofield $2006,54)$. ¿No se evidencian en estos casos ciertos elementos propios de una "reconstrucción", esto es, en palabras de Honneth, de un "intento de poner al descubierto en las instituciones y en las prácticas de la propia realidad social ideales normativos que puedan resultar adecuados para criticar la realidad existente" (Honneth 2009, 58)?

Antes de dar una respuesta certera, convendría además rememorar que la articulación argumentativa de la República empieza, como bien señala Campese, desde una "fenomenología de las opiniones" sobre la justicia (citado por Gutiérrez 2017, 48). Es precisamente a partir del examen detenido de cada una de estas concepciones ordinarias sobre lo justo que habrá de entretejerse la propuesta crítica de Platón. En efecto, cuando a Céfalo se le atribuye que la justicia consiste en "decir la verdad y devolver a cada uno lo que de él se ha recibido" (331c); o cuando Polemarco, citando al poeta Simónides, postula que "es justo devolver a cada uno lo que se le debe" (331e) y, posteriormente, que "la justicia es beneficiar a los amigos y perjudicar a los enemigos (334b); o cuando Trasímaco afirma que "lo justo no es otra cosa que lo que conviene al más fuerte" (338c): ¿no se trata de concepciones vulgares $\mathrm{o}$, si se prefiere, comunes de la justicia? Más aún,

3 Todas las traducciones de los textos cuyas referencias bibliográficas están en inglés o alemán son propias. 
¿no es mediante la elucidación de los casos en que tales máximas se muestran como apropiadas o inapropiadas que Platón desarrollará pedagógica y políticamente su ascenso (anábasis) a los principios? ${ }^{4}$ Hasta ahora, parece innegable que Platón parte, como diría Walzer, de la moralidad existente, incorporando así elementos reconstructivos en la articulación de su crítica a la sociedad. No obstante, ¿en qué medida el decurso mismo de la obra conserva verdaderamente dichas opiniones al momento de superar su carácter unilateral?

Acaso podría pensarse que, como alega Sachs, "los intentos por mostrar que la justicia platónica implica [entails] la moralidad ordinaria están sorprendentemente ausentes en la República" (1963, 154). Sin embargo, a pesar de su carácter provocador, dicha tesis pareciera no condecirse del todo con el desarrollo argumentativo del diálogo. No sin tino, Gutiérrez llama la atención sobre el hecho de que, tras el cierre aporético del libro I en lo que respecta a la búsqueda de una definición adecuada de la justicia, el libro II procederá a examinarla desde la pregunta acerca de qué modo de vida (bíou diagôgê) resulta más provechoso elegir, el justo o el injusto: "De esa manera, se introducen los tres argumentos finales de Sócrates, que, conjuntamente, constituyen 'los aspectos de una única concepción ontológica' [de la justicia] y, como tal, un esbozo anticipado de la concepción por desarrollar en el resto del diálogo" $(2017,66)$. La aclaración paulatina y, en particular, la recurrencia de los argumentos de la pleonexía, de la cooperación y de la coincidencia entre función (érgon) y virtud (aretê)

4 El énfasis en el componente pedagógico y político de la anábasis se debe a que, como bien señala Gutiérrez (2017), la discusión con estos primeros tres interlocutores se desenvuelve aún en el ámbito de la eikasía. Se trata, por tanto, de una representación de la katábasis política y pedagógica de Sócrates a la caverna, tras haber contemplado la Idea del Bien; hecho que se evidencia claramente desde el uso del verbo katabaínô como palabra inaugural de la República (327a). Por lo tanto, si bien ello podría reforzar la idea de que la crítica platónica parte de criterios preconcebidos que han de aplicarse mecánicamente, es de hecho a través del diálogo y la confrontación con las opiniones que la crítica puede realizarse como tal: "Semejantes sombras requieren de la intervención del filósofo para ser puestas al descubierto, razón por la cual este desciende a la caverna a disputar sobre las sombras de la eikasía y a intentar instaurar nuevas sombras mediante nuevos modelos formativos" (57). Es más, ¿hasta qué punto sería o no desafortunado caracterizar dicho descenso, justamente, como una suerte de Ideologiekritik? 
ponen de manifiesto la unidad que subyace a toda la obra ${ }^{5}$. En tal sentido, concordamos con Kosman al sostener que "la dialéctica de Platón, en su búsqueda por una definición, apunta al descubrimiento no de una fórmula privilegiada, sino del entendimiento adecuado de las múltiples fórmulas que la tradición suministra a los doctos" $(2007,126)$. Así pues, lejos de apelar en última instancia a una "revelación", el ejercicio dialéctico en sentido lato consiste, como bien indica Rowe, en una elucidación dialógica: "la dialéctica en Platón siempre ha sido acerca de elucidar cómo es que las cosas son, a través del medio de la conversación" $(2007,35)^{6}$.

No obstante, nuestro énfasis en los elementos reconstructivos que atraviesan la obra de Platón no debe hacer que pasemos por alto otro aspecto crucial, a saber: su propuesta política se forja conforme al razonamiento (katà lógon) y en función a acuerdos argumentativos con sus interlocutores. En palabras de Gutiérrez, ello se hace particularmente patente en el caso de la hipótesis acerca de que "el mayor bien para la polis es "aquello que la junta y la hace una" y el mayor mal, aquello que "la disgrega y la hace múltiple" (462a9-b3)" $(2017,118)$. Si bien convendría mencionar desde ya que dicha hipótesis terminará por fungir como el principio de justicia y de unidad, de momento bastará que enfaticemos lo siguiente:

En general, las leyes que se deducen a partir de la hipótesis llegan a tal nivel de concreción que podría uno olvidar la insistencia de Sócrates en que el paradigma del buen Estado propuesto por él es un modelo trazado en el argumento o discurso (tô lógô, 473a5-b1), cosa que no hay que perder de vista, puesto que toda legislación de Kallípolis debe, según el método, derivarse de la hipótesis. $(2017,120)$

¿No habría ahí elementos propios de una "construcción" o, siguiendo de cerca a Honneth, un "intento de servirse de un método de justificación susceptible de aprobación general para llegar a principios normativos [universales] a la luz de los cuales se pueda criticar fundadamente el orden institucional de una sociedad" $(2009,58)$ ? En efecto, no es casual que

5 De hecho, la tesis central del texto de Gutiérrez-esto es, que la estructura de la República está determinada por los símiles del sol, la línea y la caverna $(2017,27)-$ es inconcebible sin presuponer que el diálogo en su conjunto articula una unidad argumentativa.

6 "Dialectics in Plato was always about getting clear about the way things are, through the medium of conversation". 
Schofield se refiera a dicha hipótesis como el Principio de Unidad (PU) -“EI mayor bien para una ciudad es lo que la hace una"- $y$, acto seguido, agregue que "a menos que una ciudad sea una ciudad, no será ciudad del todo. Su propia identidad como ciudad es una función de su unidad" $(2006,215)$. En otras palabras, Platón formula un principio trascendental que se remite racionalmente al concepto y, por ende, a la determinación misma de polis?. Ahora bien, es necesario reconocer que dicho principio no es, como en el caso de típicos modelos constructivos, procedimental. Por el contrario, a Walzer no le falta razón al indicar que Platón descubre o, mejor dicho, desoculta (en el sentido de alêtheia) la Idea del Bien como un valor objetivo o, más aún, como el principio no hipotético que constituye la realidad (1987, 19). Sin embargo, creemos haber ofrecido argumentos suficientes para defender que, en todo caso, ello no justifica en lo absoluto reducir el proyecto de la República a la mera "vía del descubrimiento" o, lo que es peor, al modelo de la "revelación". Tanto los diversos presupuestos hermenéuticos de la obra, así como su proceder dialógico y racional, encarnan elementos constructivos y reconstructivos que, en última instancia, no hacen sino poner de manifiesto la complejidad de la propuesta platónica. Así pues, más allá de las consideraciones metodológicas presentadas, convendría explorar ahora en qué sentido el contenido mismo de dicha crítica es, o no, filosóficamente relevante para el debate contemporáneo.

\section{§3. Unidad y stásis: fundamentos de la Teoría crítica}

Quizás el leitmotiv más recurrente a lo largo de la historia de la filosofía sea, por desgracia, el arte de malinterpretar a nuestros predecesores en nombre de la innovación. Desde esta óptica, las críticas de Aristóteles a Platón no hacen sino inaugurar, en cierto sentido, una larga lista de calumnias y

7 Desde dicha óptica, ¿qué habría de verdaderamente sorprendente en la comparación que Schofield establece a continuación entre el PU y el modelo de constructivismo político por antonomasia, esto es, la concepción rawlsiana de la justicia? "Hay más en común entre el PU y los principios a los que Rawls suscribe de lo que uno podría suponer. A pesar de su conocida doctrina acerca de la prioridad de lo correcto por sobre lo bueno, Rawls insiste en que, en realidad, ambos son complementarios, y esto, implícito en la justicia como equidad, es una idea del bien de la sociedad política como tal. Aquel bien consiste (así como en la República) en la unidad social" $(2006,217)$. 
acusaciones que aún hoy persisten en las aulas y en diversos escritos que, no sin ironía, llamamos académicos. Sin embargo, justamente en respuesta a esta tendencia, el redescubrimiento de autores clásicos a veces devela sutilezas conceptuales que habían caído en el olvido y que, en cambio, despliegan toda una serie de recursos filosóficos para reflexionar sobre nuestro presente o, en todo caso, comprender mejor nuestro pasado. De hecho, la manera en que Honneth se reapropia de la Filosofía del derecho de Hegel es, quizás, un ejemplo maravilloso: contra el estereotipo inaugurado por Marx y defendido a capa y espada por autores como Jürgen Habermas o Ernst Tugendhat ${ }^{8}$, Honneth vio en la FD no una mistificación ideológica del Estado prusiano - la cual solo podría desembocar en un conservadurismo que suprima hasta el último rastro de individualidad genuina-, sino todo lo contrario, esto es, un potencial crítico para repensar normativamente nuestras sociedades desde una concepción social de la libertad. La pregunta pareciera entonces caer por su propio peso: ¿hasta qué punto dicha reivindicación de Hegel como un interlocutor decisivo para la Teoría Crítica descansa, o no, en la influencia de Platón?

Una primera pista para abordar dicha interrogante puede encontrarse, curiosamente, en los prejuicios de Karl Popper, quien sostiene que "bajo la influencia de la doctrina platónico-hegeliana sobre la preeminencia del Estado en comparación con el individuo, Marx desarrolló la doctrina de que la 'conciencia' del individuo está determinada mediante condiciones sociales" (1980, 664-665). A pesar de que se trate de una interpretación con matices altamente cuestionables, el vínculo que Popper establece entre Platón y Hegel resulta, por lo menos, ilustrativo. En efecto, la filosofía política de ambos autores, mutatis mutandis, enfatiza que no es posible pensar cabalmente la justicia o la libertad de manera unilateral, sino desde la relación recíproca entre el individuo y la sociedad que este cohabita. Así, Platón se opuso a los sofistas, quienes pregonaban que uno solamente debe adaptarse de manera estratégica a las 'verdades' imperantes en la polis; Hegel, por su lado, se opuso a los modernos, quienes partían de una

8 No es preciso olvidar, sin embargo, las acérrimas declaraciones de Schopenhauer, quien caracteriza a Hegel como "un charlatán repulsivo y trivial, y un escritorzuelo del sinsentido sin precedente" [Einen widerlichen, geistlosen Scharlatan und beispiellosen Unsinnschmierer, Hegel] $(1913,85-86)$. 
concepción estática, atomista y autorreflexiva de la subjetividad. Prestemos atención a este último aspecto. Como es sabido, tal será uno de los ejes centrales que el pensamiento de Marx y toda la Teoría Crítica heredarán de Hegel, a saber: que es necesario pensar dinámicamente la constitución de la subjetividad y sus posibilidades de autorrealización desde las múltiples interrelaciones que esta entabla con el entorno social.

Ahora bien, la imagen anquilosada de Hegel como un pensador de la totalidad ha hecho que, en no pocos casos, "se arroje al bebé junto con el agua de la bañera". Por ejemplo, Ikäheimo constata que, sobre todo en el mundo angloparlante, existe aún hoy "una casi completa falta de teorización sobre la constitución social de las personas y su entrelazamiento [intertwinement] con la constitución del resto del mundo social e institucional" $(2011,146)$. Justamente en virtud de dicha carencia, los planteamientos de Hegel en torno al espíritu (Geist) y la vida ética (Sittlichkeit) han cobrado particular relevancia en los últimos años. Es en tal sentido que Ikäheimo da cuenta de la vigencia del holismo hegeliano, esto es, la propuesta por comprender al mundo social y a los individuos como un todo estrechamente interconectado y que deviene conforme a ciertos principios comprehensivos que lo gobiernan $(2011,150)$. No obstante, ¿acaso dicho enfoque no se encuentra ya prefigurado en la República y, más precisamente, en la 'analogía' entre la estructura del alma y la de la ciudad ideal? En efecto, la interrelación entre ambas es patente, como bien muestra Koyré:

Puesto que la analogía [platónica] descansa sobre una interdependencia mutua, es imposible estudiar al ser humano sin estudiar al mismo tiempo la ciudad de la cual forma parte. La estructura psicológica del individuo y la estructura social de la ciudad encajan perfectamente o, en términos modernos, la psicología individual y la psicología social son mutuamente interdependientes. (citado por Schofield 2006, 35)

En este sentido, Schofield tiene razón al recalcar que el análisis de Platón "asume y enriquece una concepción de los seres humanos como animales políticos cuyas motivaciones poseen una dimensión social inevitable" $(2006,252)$. 
Sin embargo, más allá de dichas constataciones relativamente triviales, la prefiguración de dicho holismo en Platón se ve con mayor claridad en aquello que, siguiendo la terminología con la que se ha caracterizado a Hegel, podríamos denominar como su "teoría orgánica del Estado" (2006, 219). Habíamos mencionado ya que, en su República, Platón se remite a la unidad como principio trascendental que permite determinar el mayor bien para la polis e, incluso, el concepto mismo de una polis. La unidad funge, en tal sentido, como criterio de justicia y, por ende, como fundamento último que legitima sus tres planteamientos centrales, a saber: la comunidad de funciones entre hombres y mujeres; la comunidad de mujeres e hijos; y la factibilidad de la polis justa mediante la coincidencia entre filosofía y poder político, lo cual remitirá, a su vez, a la comunidad de las ideas. Es necesario ahora considerar este principio a la luz de la relación entre individuo y sociedad: como bien indica Gutiérrez, "la unidad interna del alma justa es condición de la posibilidad de la unidad de la polis justa, la manifestación del conflicto y la disensión en el alma injusta es la desintegración de esta unidad (432d4-6), el mal mayor para la polis" (2017, 228). En otras palabras, la participación (méthexis) en la idea de unidad es aquello que permite realizar y armonizar recíprocamente el bien individual y el bien común. No ha de extrañarnos: después de todo, Kosman tiene razón al enfatizar que "una idea es un principio de compleción estructurada [structured wholeness; holon], no meramente una totalidad colectiva [collective totality; pan]" (2007, 134). Entonces, por emplear una expresión corriente, se diría que tanto la persona justa como la polis justa -en tanto cada una es un todo orgánico que participa de $y$, por ende, se asemeja a la idea de unidad- son 'más que la suma de sus partes'.

A este respecto, un término que no debe pasar desapercibido es, precisamente, el de comunidad (koinônía). De nuevo, en palabras de Gutiérrez, la propuesta política de Platón consiste en defender que "una comunidad en la que todos están emparentados con todos, en la que todos dicen "mío" y "no mío" del mismo modo y sobre las mismas cosas queda libre de contradicciones y exenta de conflictos (461e-466d)" (2017, 227). Esto significa que la unidad de la polis justa habría de resolver las contradicciones propias de aquellas 'polis' que se encuentran más bien divididas (i.e., 
timocracia, oligarquía, democracia, tiranía, etcétera), ya que en ellas reina la particularidad, la pleonexía y, lo peor de todo, la stásis:

En consecuencia, cada una de las "polis" deficientes será, en verdad, una multiplicidad ilimitada. Y, precisamente por ello, hay en ellas una tendencia hacia la desintegración, lo cual se hace manifiesto en el conflicto que impera en todas ellas, no solo entre ricos y pobres, sino entre los muchos y los pocos, entre los gobernantes y el pueblo. $(2017,235)$

Salvando las distancias, ¿no es exactamente esta la crítica que Hegel articula contra la "sociedad civil" (bürgerliche Gesellschaft) o, con mayor precisión, contra lo que nosotros llamaríamos "el mercado"? No es casualidad que en la Filosofía del Derecho se describa esta esfera de relaciones estratégicas, contractuales y orientadas hacia la satisfacción de intereses privados, como un "estadio de la diferencia" o, peor aún, como la "pérdida de la vida ética" (Verlust der Sittlichkeit) (Hegel1821, § 181).

En efecto, el mercado se caracteriza por ser una esfera donde "cada uno es fin para sí mismo y todos los demás no son nada para él. Pero sin relación [Beziehung] con los otros [uno] no puede alcanzar la extensión de sus fines; los otros son, por lo tanto, medios para el fin del individuo particular" (Hegel 1821, § 182, Ag.). Por consiguiente, a la deriva de sus impulsos, "la particularidad para sí, en cuanto satisfacción en todas direcciones de sus necesidades, del arbitrio contingente y del gusto [Belieben] subjetivo, se destruye a sí misma en su goce [Genüssen] y destruye su concepto sustancial (...) [dando lugar al] espectáculo tanto del libertinaje, de la miseria y de la corrupción física y ética que es común a ambos" (Hegel 1821, § 185). En tal sentido, la propuesta política del Estado hegeliano consistirá, así como en el caso de Platón, en resolver las contradicciones propias de la sociedad civil en tanto esfera que promulga el mayor mal para la polis, es decir, la stásis. Por consiguiente, el Estado, a la manera de la polis justa, habrá de efectuar una superación (Aufhebung) de dicha multiplicidad indeterminada en una unidad ética donde se alcance, por emplear una conocida formulación de Hegel, "un yo que es un nosotros, y un nosotros que es un yo" [Ich, das Wir, 
und Wir, das Ich ist] $(2018,139)^{9}$. En tal sentido, también Hegel comprende al Estado como una koinônía que se realiza según el modelo de la "Idea" en tanto determinación racional del individuo y de la sociedad ${ }^{10}$.

Ahora bien, es crucial recordar que Platón establece una importante analogía entre el mayor mal para la polis -esto es, la stásis entendida como injusticia- y la enfermedad del cuerpo (444c-d). En palabras de Gutiérrez, se diría que "justicia e injusticia se relacionan entre sí como salud y enfermedad, como un estado conforme y otro contrario a la naturaleza [parà phýsin kaì katà phýsin], como unidad y multiplicidad" $(2017,170)$. Incluso, en el libro VIII de la República, se hará alusión a una polis enferma (nosôdês) que, ante el menor pretexto, "arde en lucha interna, aunque a veces esta revuelta estalla [stasiádzei] también sin necesidad de nada exterior" (556e). En efecto, ¿no es esta una clara prefiguración del concepto, tan importante para la Teoría Crítica, de patología social? Se precisaría aclarar, cuanto menos, dos aspectos. En primer lugar, el mismo Honneth entiende a dichas

9 A este respecto, convendría mencionar que, como bien señala Schofield, una diferencia importante entre ambos autores es que Hegel, a diferencia de Platón, consideraba a la propiedad privada como un componente básico que debe ser conservado en el tercer momento de la Sittlichkeit: el Estado $(2006,1)$. Sin embargo, esta divergencia no pareciera ser lo suficientemente problemática para poner en tela de juicio las similitudes estructurales que ambos planteamientos comparten.

10 Si bien no es preciso confundir a la Idea hegeliana con el eidos platónico y un análisis comparativo al detalle entre ambos escaparía a los propósitos del presente texto, será necesario hacer por lo menos dos acotaciones. En primer lugar, se suele pensar, con cierta razón, que la dialéctica de Hegel es inmanente, mientras que la propuesta de Platón es trascendente. Convendría, sin embargo, matizar. En efecto, a pesar de que autores como Fine (2003) o Nails (2012) insistan en que las formas platónicas no son trascendentes ni poseen una existencia independiente a los objetos sensibles, concordamos más bien con Devereux, quien distingue entre la trascendencia de las formas, por un lado, y sus "caracteres inmanentes" o manifestaciones, por otro; en tal sentido, "la separación platónica de las formas no involucra un abandono completo de la inmanencia" $(1999,225)$. Hay, por lo tanto, una separación (chôrismós) y una trascendencia, sí, pero que no puede ser absoluta respecto de lo sensible. De lo contrario, caeríamos justamente en una de las aporías que Platón mismo tematiza en su Parménides, esto es, la de concebir dioses que, por habitar en un mundo inteligible radicalmente separado, "ni son nuestros señores ni saben de los asuntos humanos" (134d-e). Curiosamente, cuando el mismo Hegel discurre acerca del carácter aprehensible [Handgreiflichkeit] de las formas, sostiene que "la idea platónica no es sino lo universal o, más precisamente, el concepto [Begriff] del objeto; algo tiene realidad efectiva [Wirklichkeit] solamente en su concepto; en tanto se diferencia de su concepto, deja de ser efectivo [wirklich], y es una nada [ein Nichtiges]" $(1969,44)$. Baste lo dicho hasta aquí para ilustrar, cuanto menos, ciertos aspectos de la influencia del concepto platónico de idea en Hegel. Como bien se mostrará a continuación, dicha influencia persiste, a su vez, en el trasfondo de los planteamientos críticos del mismo Honneth. 
patologías como la pérdida de ideales comunitarios y cooperativos propios de un universal racional, entendido como ideal normativo necesario para la autorrealización del individuo en sociedad (2009, 32, 42, 47). Desde esta definición, ¿no sería preciso clasificar a la stásis justamente como una disgregación patológica de la vida social, como una ruptura de la unidad o, desde Hegel, como la pérdida del "nosotros"?

De hecho, Honneth sigue dicha línea argumentativa al desarrollar su reconstrucción histórica del mercado; así, ofrecerá el siguiente diagnóstico: "todo lo que correspondería a una esfera de libertad institucionalizada está notoriamente ausente del sistema económico actual" $(2014,232)$. El mundo laboral es, en este caso, paradigmático: según Honneth, no solo es cierto que, "para la mayoría de asalariados, en los últimos veinte años las oportunidades de saberse integrado como un par entre pares en el contexto de cooperación del mercado capitalista se han reducido en vez de haber aumentado" (2014, 330-331). Asimismo, dichas injusticias no suscitan ya respuestas colectivas de rechazo o indignación, sino que predomina la privatización patológica del descontento, la enajenación comunicativa, la individualización de la atribución de responsabilidades y, en suma, la disolución de un "nosotros" que comprenda al mercado como un organismo social de reciprocidad no coercitiva (2014, 332-335). A propósito del problema de la privatización de malestares sociales, es sorprendente hasta qué punto ello se condice, mutatis mutandis, con la propuesta platónica de una polis donde impere la "comunidad de placer y dolor" (hêdoês kaì lýpês koinônía) y, más bien, se evite a toda costa la "particularización" (idíôis) de tales estados de ánimo (462b). Más aún, es imperativo enfatizar que, como bien sostiene Stephen Halliwell, "Platón parece haber de hecho acuñado el sustantivo abstracto 'privatización' (idiôsis) -el cual nunca habría de usar de nuevo- para caracterizar la condición de nuestras emociones en tales circunstancias [de disgregación social, de stásis]" (citado por Schofield, 2006, 222).

En segundo lugar, la connotación médica y biológica del término "patología" no es fortuita, sino que remite a una comprensión holista o, más precisamente, organicista de la sociedad. En este sentido, estamos de acuerdo con Laitinen \& Särkelä, quienes indican que es posible encontrar 
planteamientos de dicha índole en la República de Platón, pasando por el positivismo de Comte, la sociología de Durkheim, la concepción hegeliana del Estado, Louis de Bonald, Joseph de Maistre y, a propósito del debate contemporáneo, autores como Franck Fischbach y, evidentemente, Axel Honneth (Laitinen \& Särkelä 2018, 9). Desde esta perspectiva diríase 'naturalista', una patología social es el resultado de una 'disfunción', 'desarrollo fallido' (misdevelopment), 'malformación' o 'desajuste' en las instituciones que atenta contra el mantenimiento y la reproducción del organismo social $(2018,9)$. Sin embargo, es interesante que ambos autores enfaticen, como nosotros, las fricciones en apariencia irresolubles que esta concepción de una patología social generaría respecto del "pensamiento posmetafísico" de la Teoría Crítica contemporánea; en concreto, ya que dicho naturalismo implica, precisamente, un compromiso con una metafísica o una cosmología que dé cuenta del tipo de similitud estructural entre la vida orgánica y la vida social, entre naturaleza y sociedad, y entre el mantenimiento del organismo y la reproducción de la sociedad $(2018,11)$. Por ello, Laitinen \& Särkelä reivindicarán una noción alternativa de las patología sociales donde el principio ontológico decisivo para concebir y juzgar la vida social no sean ya el auto-mantenimiento y la estabilidad orgánica, sino el crecimiento $(2018,14) . / /$

En lo que nos concierne y contra ciertas interpretaciones organicistas de Hegel a las cuales, incluso, hemos hecho referencia, se diría desde este último enfoque que la teoría hegeliana del Estado resulta menos importante que su concepción de lo social como 'autoconsciente' o vida 'superada' (sublated life; aufgehobenes Leben), la cual se evidencia en las dinámicas de reconocimiento recíproco (wechselseitige Anerkennung) propias de la socialidad (Laitinen \& Särkelä 2018, 15). En otras palabras, esta cosmología del crecimiento afirma que la vida social ha emergido (grown out) de la vida orgánica, pero con mayor complejidad e intensidad, de manera irreductible y, no obstante, siendo todavía un tipo de proceso vital (2018, 15). En concreto, se diría que la vida social puede devenir patológica de dos maneras: o bien pierde su crecimiento transformativo y se estanca en un proceso meramente orgánico, o bien no logra reproducir su forma y degenera en mera procesualidad inorgánica $(2018,15)$. Desde este trasfondo, puede apreciarse la agudeza crítica de Adorno, por ejemplo, al denunciar 
la tendencia hacia un "mundo administrado" (verwaltete Welt) o hacia una "sociedad socializada" (vergesellschaftete Gesellschaft), donde lo propiamente patológico no es su carácter disfuncional, sino su funcionamiento de auto-mantención o, incluso, de automatización: en palabras de Laitinen \& Särkelä, "la vida social literalmente muere cuando meramente mantiene su forma, porque entonces degenera en una mera vida orgánica" $(2018,15$ 16). ¿Se diría entonces que, bajo esta última concepción de las patologías sociales, el énfasis platónico en la com-unidad como criterio de justicia para la polis quedaría, a fin de cuentas, desacreditado?

Sostenemos lo contrario. En efecto, no es casual que el término utilizado por Platón para describir el mayor mal en la polis sea, precisamente, stásis. Con justa razón, aquel concepto suele traducirse en el marco de la República como un antónimo de "unidad", por ejemplo: escisión, secesión, disensión, disgregación o disputa.Y sin embargo, no es preciso olvidar que, de acuerdo con Pabón, stásis también significa "estabilidad" o "fijeza" (2008, 543). Ahora bien, a pesar de que dicho recurso etimológico luzca trivial y un tanto ad hoc, no estaría de más preguntarnos: ¿por qué Platón, siendo un escritor de una sutileza extraordinaria, elegiría ese término y no otro? Quizás una pista se encuentre, de nuevo, en la obra de Hegel. Contra los estereotipos que retratan al ámbito inteligible como una esfera meramente estática e inmutable, Hegel señala, no sin lucidez, lo siguiente: "Platón opone a esto que al verdadero ser no se le puede negar el movimiento, la vida, el alma ni el pensamiento, y que la sagrada razón no puede darse nunca ni en nada, si se trata de algo inmóvil" (citado por Montecinos 2009, 121). En otras palabras, el punto de que la polis participe de y se asemeje a la idea de unidad no consiste en alcanzar un estancamiento perenne, sino en la realización de la vida social conforme a su naturaleza y función propia (katà phýsin kaì katà érgon). Como bien indica Kosman, "en una ciudad justa, cada persona ejerce la ocupación para la cual tiene la virtud apropiada" $(2007,128)$. Por el contrario, en una 'polis' dividida, la ausencia de armonía y de cohesión tanto a nivel social como a nivel individual impedirán que los ciudadanos ejerzan aquellas actividades para las cuales están mejor capacitados, ya que cometerán injusticia los unos contra los otros e, incluso, contra sí mismos. Por tales motivos, la desintegración conlleva al estancamiento y, a fortiori, 
a la degeneración; la unidad, en cambio, a la aretê, a la eudaimonía o, en términos de Laitinen \& Särkelä, al 'crecimiento' de la vida social ${ }^{11}$.

A modo de cierre, convendría quizás tomar en consideración el caso del filósofo, quien no ha de quedarse aislado en una posición (stásis) contemplativa respecto de las ideas, sino retornar a la polis para actuar (práttein), en palabras de Gutiérrez, como un "demiurgo de la aretê" (2017, 203). La referencia no es en lo absoluto baladí. De hecho, podría objetarse que el Demiurgo, según se indica en el Timeo, toma como modelo del mundo al "ser siempre inmutable" (28a), es decir, a las ideas. ¿No sería esto contradictorio con nuestra interpretación, acaso demasiado caritativa? A ello convendría responder que la expresión empleada para designar a las ideas, aeì katà tautà ón, bien podría traducirse como "aquello que es siempre conforme a sí mismo", esto es, conforme a su naturaleza, función, determinación o, en términos de Hegel, concepto; aquello que es siempre idéntico a sí, que nunca perece (apollýô) y, por lo tanto, no está sujeto a la desintegración. Ello no tiene por qué sugerir una 'inmutabilidad' en el sentido de mera fijeza o estancamiento. Es más, si las ideas fueran efectivamente estáticas, sería imposible la koinônía y, por implicación, el hecho fundamental de que, en virtud de sus relaciones con otras ideas, "cada una aparece múltiple" (476a). Por otro lado, no es preciso olvidar que la praxis del Demiurgo también es constante, ya que todo lo que existe (incluido, aunque en menor medida, el ámbito inteligible) está compuesto de límite (tò péras) y de lo ilimitado (tò ápeiron), como bien se evidencia en el Filebo (23c). Así pues, Gutiérrez tiene razón al indicar que el filósofo, en tanto que ha de imitar y hacerse semejante a este "modelo divino", no apunta solo a "conservar un orden justo, sino a la instauración de un modelo aún no plasmado" $(2017,205)^{12}$.

11 Es importante desligar este concepto de sus resonancias económicas, ya que el hecho de administrar o gestionar la vida social en función a la pleonexía corresponde, más bien, a que la vida social degenere en vida orgánica y, lo que es peor, se llegue a atentar incluso contra la pervivencia misma de dicha vida orgánica, como es patente con la crisis climática de nuestros días.

12 Este punto es crucial y amerita de, cuanto menos, dos aclaraciones. En primer lugar, concordamos con Morrison al distinguir entre una utopía, en tanto descripción de una sociedad imaginada que es mejor que cualquier sociedad existente o que haya existido, y una "mera utopía", en tanto descripción de una sociedad irrealizable $(2007,232)$. Habiendo mencionado ya, aunque sea escuetamente, que Platón elabora su demostración de la factibilidad de la polis justa mediante un recurso a la comunidad de las ideas, sobra decir que ningún lector 
Por supuesto, toda esta praxis político-filosófica requerirá de un esfuerzo siempre renovado por limitar la tendencia hacia la indeterminación (apeiría) que predomina en el ámbito sensible y que, en el caso de la sociedad, se le conoce como stásis.

\title{
$\S 4$. Conclusiones
}

\author{
En su célebre Dialéctica de la llustración, Adorno \& Horkheimer dan cuenta \\ de una paradoja: la llustración, en tanto movimiento histórico que pretendía \\ librar a los hombres del mito y del miedo, ha recaído en mitología. ¿Por qué? \\ Por un lado, porque en el mito se encontraba ya la pretensión por explicar
}

atento clasificaría a la República como una "mera utopía". En segundo lugar, tampoco es preciso comprender la acción del filósofo en términos de una simple producción instrumental o, más precisamente, de aquello que Arendt denomina como making: según ella, "en la República, el rey filósofo aplica las ideas como el artesano aplica sus reglas y estándares; él 'produce' [makes] su Ciudad como el escultor hace una estatua, y en la obra platónica tardía estas mismas ideas se han convertido incluso en leyes que solo necesitan ser ejecutadas" $(1958,227)$. Por el contrario, dicha interpretación pasa completamente por alto el carácter dialógico que es propio de la obra de Platón y, en este caso, del quehacer filosófico. Si bien hay un cierto componente que podríamos denominar como "paternalista", en tanto el filósofo habla desde una posición de "saber", ello no es equiparable a la mera coerción. No en vano Euben identifica, hasta cierto punto, una "dimensión habermasiana" en los diálogos, donde la comunicación está regida por nociones de honestidad, entendimiento recíproco, consenso y argumentación racional (citado por Schofield 2006, 56). De hecho, es interesante notar que, como bien señala Neschke, el accionar paradigmático del Demiurgo en el Timeo se rige no por el modelo de la violencia (biádzô), sino por el de la persuasión (peithô) (2000, xxiii). Por tal motivo, estamos de acuerdo con Schofield al señalar que incluso el modelo legislativo propio de las Leyes "debe involucrar una forma de persuasión que es comparada con la discusión filosófica" $(2006,57)$. Ello se ilustra, por ejemplo, en la importante distinción entre el "doctor esclavo", quien da órdenes a sus pacientes, y el "doctor libre", quien "no da ninguna prescripción hasta obtener el consentimiento [sympeithô] del paciente y solo entonces, asegurando su cooperación continua por medio de la persuasión [metà peithoûs], intenta completar la tarea de restaurar su salud" (720d-e). En otras palabras, el "rey filósofo" no es ningún tirano. Y sin embargo, tampoco un ingeniero, en el sentido de que no recurre (no puede recurrir) a una aplicación mecánica y unilateral de las ideas para "producir instrumentalmente" la polis justa. A este respecto, podríamos concordar con Sedley, quien sostiene que "uno puede 'saber' [know] lo que es la justicia, pero nadie, ni siquiera un filósofo, puede 'saber' análogamente que esta política [policy] o aquella es justa, dado que solo en ciertas circunstancias o desde algún punto de vista esa misma política es también injusta" $(2007,260)$. No obstante, es necesario matizar que hay, sí, un "conocimiento de las apariencias en cuanto apariencias", el cual se deriva del conocimiento de las ideas y le sirve al filósofo para discernir y orientarse de mejor manera en la caverna, como bien señala Gutiérrez (2017, 160-161). Caso contrario, si el conocimiento fuera exclusivamente extra-mundano, sería inútil en la esfera política, y la República se convertiría, así, en una "mera utopía". 
(Erklären) y por ende dominar la realidad: de este modo, "el mito se disuelve en Ilustración y la naturaleza en mera objetividad" $(2009,64)$. La doctrina del positivismo habría de reproducir paradigmáticamente las tendencias fundamentales que impulsaron, otrora, los mitos; pero con una diferencia crucial: "En el camino hacia la ciencia moderna los hombres renuncian al sentido. Sustituyen el concepto por la fórmula, la causa por la regla y la probabilidad" $(2009,61)$. En otras palabras, se erradica del imaginario social de la modernidad el intento paralelo de los mitos por comprender (Verstehen) el mundo y sus orígenes: en efecto, los datos han matado a los relatos y se han erigido a sí mismos, impertérritos, como la única verdad admisible. Tal es, en líneas generales, la dialéctica de la llustración. Habría entonces que preguntarnos entonces: ¿cuánto de todo esto se refleja en el legado mismo de la Teoría Crítica?

Como bien indica Freyenhagen, los trabajos de la primera generación $y$, en particular, de Adorno \& Horkheimer echaron luz sobre una serie de dificultades para alcanzar criterios legítimos que permitan fundamentar cualquier crítica social con pretensiones de seriedad y validez: ante tamaños impases, Habermas y sus seguidores emprendieron una insaciable búsqueda de superación (Aufhebung) de estas aporías mediante aquello que podríamos denominar como un programa de "fundamentación" [Begründungsprogramm], el cual habría de demostrar la rectitud moral de sus estándares críticos $(2017,1-3)^{13}$. Honneth no ha sido, pues, la excepción:

13 Es muy importante realizar una salvedad a este respecto: a pesar de utilizar explícitamente el término Begründung, resulta cuanto menos llamativo que Freyenhagen traduzca dicho concepto al inglés como "justification", ya que este último concepto remite, más bien, al alemán Rechtfertigung. De hecho, en un artículo anterior, Freyenhagen señala que Adorno, en lo que concierne a la problemática de cómo darle un soporte racional a su crítica de la sociedad, distingue entre una fundamentación (Begründung, grounding) y una justificación/ vindicación (Rechtfertigung, vindication), rechazando solamente la primera y optando, más bien, por la segunda $(2012,183)$. Si bien una discusión detallada de ambos conceptos escapa a los propósitos y posibilidades de este artículo, bastará decir que, en líneas generales, el término Begründung refiere a una fundamentación positiva y apodíctica que, en cierto sentido, ha de seguir el modelo de las ciencias formales y naturales, mientras que el término Rechtfertigung remitiría más bien a una justificación o vindicación racional en sentido lato. Un problema ulterior es, sin embargo, la apropiación contemporánea del término Rechtfertigung para dar cuenta de una justificación moral de carácter discursivo y universalista, como sucede con Rainer Forst (2007) y su derecho a la justificación. En cualquier caso, la crítica de Freyenhagen apuntaría justamente a que este tipo de Rechtfertigungen siguen en última instancia el modelo de una Begründung. 
sus esfuerzos por distinguir entre tres modelos de crítica y, acto seguido, elaborar una teoría de la justicia desde un análisis de la sociedad responden, efectivamente, a esta tendencia. Lo particularmente curioso es que, de la mano con los representantes de las nuevas generaciones de la Teoría Crítica, se rehúya hasta el más mínimo compromiso metafísico para justificar (o incluso fundamentar) sus criterios normativos $y$, al hacer esto, se tienda a dejar de lado intuiciones importantes de pensadores clásicos como Hegel o Platón. Así, perdemos de vista el origen (archê) de los conceptos mismos con los cuales queremos hacer crítica social; recaemos, acaso, en mitología. ¿Sería esta, pues, una dialéctica de la justicia?

Nuestra tesis es simple: aquel Begründungsprogramm que caracteriza a la Teoría Crítica contemporánea se remonta en última instancia a, valgan verdades, la obra de Platón y, más precisamente, a la unidad como criterio trascendental de justicia. De este modo, cuando Honneth desarrolla sus propias reconstrucciones normativas de la sociedad desde una perspectiva holista y no sin denunciar la privatización de malestares como una patología social decisiva, participa inevitablemente de la tradición crítica inaugurada por Platón. En un sentido lato, podría incluso decirse que él mismo está representando, en su quehacer, eine Art von Platonismus. Quizás no lo sabe, pero lo hace. Por todos estos motivos, si bien no es preciso pasar por alto las diferencias importantes $y$, en ciertos aspectos, irreconciliables que separan a Platón de la crítica social contemporánea, tampoco sería justo dejar de reconocer su relevancia filosófica. Mucho menos si lo que se pretende es fundamentar (o justificar) una teoría de la justicia. Por nuestra parte, esperamos haber contribuido a mostrar cómo algunos de los componentes metodológicos y conceptos clave de la República arrojan luces acerca de los problemas que, hoy, atraviesan aquella nuestra vida social.

Recibido: $25 / 03 / 2020$ Aceptado: 08/05/202 


\section{Bibliografía}

Adorno, Th. \& Horkheimer, M., 2009. Dialéctica de la llustración. Madrid: Editorial Trotta.

Devereux, D., 1999. Separation and Immanence in Plato's Theory of Forms. En: Plato 1: Metaphysics and Epistemology, ed. Gail Fine. Oxford: Oxford University Press.

Fine, G., 2003. Plato on Knowledge and Forms. Oxford: Oxford University Press.

Freyenhagen, 2012. Adorno's Critique of Late Capitalism: Negative, Explanatory and Practical. En: Conceptions of Critique in Modern and Contemporary Philosophy, ed. Boer, K. London: Palgrave Macmillan.

Freyenhagen, 2017. What is Orthodox Critical Theory?. World Picture, 12. Disponible en: http://www.worldpicturejournal.com/WP_12/pdfs/Freyenhagen_WP_12a. pdf.

Forst, R., 2007. Das Recht auf Rechtfertigung. Elemente einer konstruktivistichen Theorie der Gerechtigkeit. Frankfurt am Main: Suhrkamp.

Giusti, M., 2014. ¿Se puede prescindir de la Ciencia de la lógica en la Filosofía del derecho de Hegel?. En: Dimensiones de la libertad, ed. Miguel Giusti. Lima: Fondo Editorial PUCP.

Gutiérrez, R., 2017. El arte de la conversión: Un estudio sobre la República de Platón. Lima: Fondo Editorial PUCP.

Hegel, G. W. F., 1816/1966. Wissenschaft der Logik I. Frankfurt am Main: Suhrkamp Verlag.

Hegel, G. W. F., 1821/1911. Grundlinien der Philosophie des Rechts. En Philosophische Bibliothek, Band 124. Leipzig: Felix Meiner.

Hegel, G. W. F., 1821/1999,. Principios de la filosofía del derecho. Traducción de J. L. Vermal. Barcelona: Edhasa.

Honneth, A., 2000. Rekonstruktive Gesellschaftskritik unter genealogischem Vorbehalt. Zur Idee der "Kritik" in der Frankfurter Schule. Deutsche Zeitschrift Für Philosophie, 48, (5), 729-737.

Honneth, A., 2009. Patologías de la razón: Historia y actualidad de la Teoría Crítica. Buenos Aires: Katz Editores.

Honneth, A., 2014. El derecho de la libertad: Esbozo de una eticidad democrática. Buenos Aires: Katz Editores.

Honneth, A., 2016. Padecer de indeterminación. En Patologías de la libertad, ed. Axl Honneth. Buenos Aires: Las cuarenta.

Ikäheimo, Heikki, 2011. Holism and Normative Essentialism in Hegel's Social Ontology. En Recognition and Social Ontology, eds. Heikki Ikäheimo y Arto Laitinen. Brill: Leiden/Boston. 
Kosman, A., 2007. The Republic's Inquiry into Proper Difference. En The Cambridge Companion to Plato's Republic, ed. G. R. F. Ferrari. New York: Cambridge University Press.

Laitinen, A. \& Särkelä, A., 2018. Four Conceptions of Social Pathology. European Journal of Social Theory, 20 (10), 1-23.

Montecinos Fabio, S., 2009. Conexiones metodológicas entre las filosofías de Platón y Hegel: la lectura hegeliana de la dialéctica platónica. BAJO PALABRA, 4, 107-124.

Morrison, D., 2007. The Utopian Character of Plato's Ideal City. En: The Cambridge Companion to Plato's Republic, ed. G. R. F. Ferrari. New York: Cambridge University Press.

Nails, D., 2012. Two Dogmas of Platonism. En: Proceedings of the Boston Area Colloquium in Ancient Philosophy 28, eds. G. M. Gurtler y W. Wians. Leiden: Brill.

Neschke-Hentschke, A., 2000. Platos Timaios: Beiträge zu seiner Rezeptionsgeschichte. Louvain/Paris: Éditions Peeters.

Pabón, J. M., 2008. Diccionario Manual Griego: Griego clásico - Español. Barcelona: VOX.

Pinkard, T., 2000. Hegel: A Biography. Cambridge: Cambridge University Press.

Platón, 1988. República. Traducción de C. Eggers Lan. Madrid: Editorial Gredos.

Platón, 1992. Diálogos VI: Filebo, Timeo, Critias. Traducción de M. Ángeles Durán \& F. Lisi. Madrid: Editorial Gredos.

Popper, K., 1980. Die offene Gesellschaft und ihre Feinde II: Falsche Propheten. München: Francke Verlag.

Rowe, Ch., 2007. The Place of the Republic in Plato. En: The Cambridge Companion to Plato's Republic, ed. G. R. F. Ferrari. New York: Cambridge University Press.

Sachs, D., 1963. A Fallacy in Plato's Republic. The Philosophical Review, 72, (2), 141-158.

Sedley, D., 2007. Philosophy, Forms, and the Art of Ruling. En: The Cambridge Companion to Plato's Republic, ed. G. R. F. Ferrari. New York: Cambridge University Press.

Schofield, M., 2006. Plato: Political Philosophy. New York: Oxford University Press.

Schopenhauer, A., 1913. Die Welt als Wille und Vorstellung. Zweiter Band. En: Schopenhauer Werke. Band 3. München: Georg Müller.

Walzer, M., 1987. Interpretation and Social Criticism. Cambridge: Harvard University Press.

Whitehead, A. N., 1978. Process and Reality: An Essay in Cosmology. New York: The Free Press. 